\title{
Two fatal cases of chromobacter violaceum infection
}

\author{
M A D Asanka Mallawaarachchi ${ }^{1}$, G K D Karunaratne ${ }^{2}$, Srilal de Silva ${ }^{3}$
}

Sri Lanka Journal of Child Health, 2009; 38: 70-71

(Key words: Chromobacter violaceum, fatal sepsis\}

\section{Introduction}

Chromobacter violaceum is a common inhabitant of soil and water in tropical and sub-tropical regions ${ }^{1}$. The first human infection caused by it was reported in Malaysia in $1927^{2}$. More than 150 cases have been reported worldwide from Vietnam, Taiwan, Japan, United States, Brazil, Argentina, Australia, Senegal and Sri Lanka ${ }^{1}$. We report 2 fatal cases of Chromobacter violaceum in Sri Lankan children.

\section{Case 1}

An 8 year old girl residing in a tsunami camp at Devinuwara was admitted to General Hospital, Matara in September 2005 with a history of fever, pain in shoulder joint and vomiting of 1 day duration. The following day she developed high fever, swelling of the shoulder joint, headache and drowsiness. She was transferred to the Lady Ridgeway Hospital (LRH) for orthopaedic opinion of focal cellulitis of upper right deltoid. On examination, right deltoid was tender, swollen and had a small necrotic area. X-ray was normal. The same day child's skin became dark and blisters developed. She had lower abdominal pain, low urine output and pulmonary oedema eventually requiring mechanical ventilation. She was treated with cloxacillin, metronidazole, cefuroxime followed by crystalline penicillin, ceftazidime and acyclovir. Two blood cultures taken at LRH on admission grew Chromobacter violaceum after overnight incubation. Child died the following day.

\section{Case 2}

A 5 month old infant from Kelaniya, a product of consanguineous parents had a normal development

${ }^{1}$ Senior Registrar in Paediatrics, ${ }^{2}$ Consultant
Microbiologist, ${ }^{3}$ Consultant Paediatrician,
Paediatric Intensive Care Unit, Lady Ridgeway
Hospital, Colombo.

(Received on 7 July 2008. Accepted on 20 August 2008) with good weight gain. There were no significant past illnesses. He had his $4^{\text {th }}$ month vaccination on 1.5.2007.He had a mild febrile reaction that day. Child developed high fever again on 5.5.2007 and had loose stools. Baby was treated with cefuroxime by a General Practitioner. The following morning parents noticed cold extremities and brought the child immediately to hospital. On the way baby had grunting. Baby was in septic shock on admission and no skin sepsis was detected. In spite of resuscitative measures at the LRH intensive care unit, baby died within $4 \frac{1}{2}$ hours of admission. Blood and nasopharyngeal aspirates taken for culture on admission grew Chromobacter violaceum the following day. Subsequently we visited their home. In one margin of their small land was a large stagnant water collection. This area was under water due to heavy rain but not their house.

\section{Discussion}

Chromobacter violaceum is a Gram negative bacillus which is non-fastidious, facultatively anaerobic, fermentative and positive for oxidase and catalase reactions ${ }^{3}$. Both pigmented and non-pigmented strains exist, though the non-pigmented strains are rare $^{3}$. The pigmented strains produce a violet nondiffusible pigment known as violacein, which gives the colonies their distinctive purple colour when plated on blood, MacConkey, or nutrient agar.

C. violaceum rarely infects humans, but when it does so, it causes skin lesions, sepsis and liver abscesses that may be fatal ${ }^{2}$. In most cases, the main portal of entry appears to be broken skin exposed to the organism through contaminated soil and water ${ }^{4}$. Diagnosis is made by culture of blood, abscess fluid and skin exudates. The organism is usually resistant to penicillins and cephalosporins ${ }^{5}$. Antibiotics that have been used to successfully treat $C$. violaceum include perfloxacin ${ }^{4}$, ciprofloxacin, amikacin ${ }^{3}$ and cotrimoxazole ${ }^{6}$.

Case 1 was from a tsunami camp and Case 2 had the infection after floods. Therefore contact with 
contaminated water is a strong possibility. Unfortunately the antibiotics used in both cases were mainly cephalosporins and penicillins to which $C$. violaceum is usually resistant. Death of both children highlights the high mortality associated with the illness. A high index of suspicion and appropriate antimicrobial therapy are required for this potentially fatal infection.

\section{References}

1. Davies ES. Chromobacterium. In: Braude AI, Davis CE, Fierer J, editors, Infectious Diseases and Medical Microbiology. $2^{\text {nd }}$ ed. Philadelphia: WB Saunders; 1986 p. 358-61.

2. Sneath PH, Whelan JP, Bhagwan Singh R, Edwards D. Fatal infection by Chromobacterium violaceum. Lancet 1953; 265: 276-7.
3. Ray P, Sharma J, Marak RSK, et al. Chromobacterium violaceum septicaemia from North India. Indian J Med Res 2004; 120: 5236.

4. Lee J, Kim JS, Nahm CH, Choi JW, Kim J, Pai $\mathrm{SH}$, et al. Two cases of Chromobacterium violaceum infection after injury in a subtropical region. J Clin Microbiol 1999; 37 (6): 2068-70.

5. Georghiou PR, O'kane GM, Siu S, Kemp RJ. Near fatal septicaemia with Chromobacterium violaceum. Med J Aust 1989; 150: 720-1.

6. Moore C, Lane J, Stephens J. Successful treatment of an infant with Chromobacterium violaceum sepsis. Clin Infect Dis 2001; 32 (6): E107-10. 